\title{
Congenital hypoplasia of depressor anguli oris muscle
}

\section{A genetically determined condition?}

\author{
C. PAPADATOS, D. AlexiOU, D. NICOlOPOUlOS, H. MIKROPOULOS, and \\ E. HADZIGEORGIOU
}

From the 1st Obstetrical and Gynaecological Clinic of the University of Athens, Neonatal Department of 'Alexandra' Maternity Hospital, and the 2nd Paediatric Clinic of the University of Athens

Papadatos, C., Alexiou, D., Nicolopoulos, D., Mikropoulos, H., and Hadzigeorgiou, E. (1974). Archives of Disease in Childhood, 49, 927. Congenital hypoplasia of depressor anguli oris muscle: a genetically determined condition? The frequency of hypoplasia of the depressor anguli oris muscle was 37 cases among 4530 consecutive births $(8 \cdot 2 \%)$. Diagnosis was based on clinical and electromyographic studies. Severe congenital anomalies were detected in 3 of the 37 cases, while another 3 newborns had minor congenital defects. In 17 of the 37 cases there were first- or second-degree relatives with lower lip asymmetry. A minimum of 13 out of the 74 parents of the probands were affected. The high incidence of affection among first-degree relatives of the probands is strong evidence of hereditary factors playing a role in the aetiology of this anomaly.

Congenital facial paralysis is rare and should suggest 7 th nerve palsy due to birth trauma. The frequency of unexplained facial asymmetry has recently been reported (Perlman and Reisner, 1973), and the patients' obstetrical history will ordinarily suggest whether the situation is congenital or acquired during the birth process.

Reports on congenital facial palsies, however, do not distinguish between a partial nerve paralysis and hypoplasia of the anguli oris muscle. Ford (1952) raised the question whether congenital facial paralysis is in fact a congenital aplasia of muscle rather than absence or congenital maldevelopment of the facial nerve nucleus or the 7 th cranial nerve itself.

Asymmetric crying facies as a minor congenital anomaly is now considered to be due to congenital absence or hypoplasia of the depressor anguli oris muscle on one side of the mouth. The diagnosis is established by electrical studies and/or the typical clinical picture which includes lower lip asymmetry during crying while forehead wrinkling, nasolabial fold depth, and eye closure remain intact and equal on both sides.

The condition is easily recognizable in newborns and Cayler (1969) described 14 infants having an asymmetric cry together with a variety of associated

Received 10 June 1974. congenital heart defects. Recently, additional cases of the 'cardiofacial syndrome' have been described by Chantler and McEnery (1971) and Pape and Pickering (1972).

This paper reports 37 examples of congenital hypoplasia of the depressor anguli oris muscle, states the incidence of the anomaly, discusses its importance as an index of congenital abnormalities, and presents evidence that the condition is genetically determined.

\section{Materials and methods}

Our material consists of all babies born consecutively in Alexandra Maternity Hospital for a 12-month period (1 August 1972-1 August 1973). 11 term and 32 preterm babies were excluded because of a serious condition at birth. 4530 neonates, examined by one of us (E.H.) within the first 24 hours of life and with a specific search for asymmetry of facial movements, were included in the study. Their families came from all over Greece and they belonged mainly to the lower socioeconomic level. The mothers of all babies with asymmetric crying facies were examined for lower lip asymmetry, but only 14 of their fathers were examined. A detailed search in affected newborns was made for associated congenital defects. They were investigated with a complete $x$-ray skeletal evaluation, ECG, and thorough evaluation of the cardiovascular system. Intravenous pyelograms were not done.

Detailed parity and delivery histories with specific 
reference to the use of forceps were obtained. Birthweight and gestational age, calculated from the last menstrual period, were recorded for each newborn. Pertinent data of all cases are given in Tables I and II.

\section{TABLE I}

Data on nonaffected and affected infants with hypoplasia of the depressor anguli oris muscle.

\begin{tabular}{l|c|c}
\hline \multicolumn{1}{c|}{ Characteristics } & $\begin{array}{c}\text { Nonaffected } \\
(4493)\end{array}$ & $\begin{array}{c}\text { Affected } \\
(37)\end{array}$ \\
\hline Incidence (\%) & - & $8 \cdot 2$ \\
Mean maternal age (yr) & 26 & $26 \cdot 8$ \\
Mean gestational age (wk) & $39 \cdot 9$ & $39 \cdot 8$ \\
Mean birthweight (g) & 3340 & 3320 \\
Delivery & 3375 & 24 \\
$\quad$ Normal & 750 & 4 \\
Forceps & 368 & 9 \\
Caesarean section & 2304 & 16 \\
Sex & 2189 & 21 \\
$\quad$ Male & & \\
Female & & \\
\hline
\end{tabular}

In 3 cases $(20,25$, and 28) all living members of the families (with the exception of great-grandparents) were examined specifically for asymmetry of facial movements.

In 15 affected babies and 5 of their parents ( 4 mothers and 1 father) with asymmetry of facial movements, electromyographic studies were done using bipolar concentric needle electrodes. Attempts were made to measure the latency of the evoked potentials after percutaneous stimulation of the facial nerve.

There were technical difficulties involved in performing these tests both because of a difficulty in precisely identifying the examined muscles as well as because of a lack of co-operation by most affected and examined individuals.

\section{Results}

Congenital hypoplasia of the depressor anguli oris muscle was detected in 37 out of 4530 neonates (an incidence of $8 \cdot 2 \%$ ). The mean maternal age of mothers of affected babies was $26 \cdot 8$ years (range 19-40 years). The mother of Case 20 suffered from

TABLE II

Clinical characteristics of affected infants

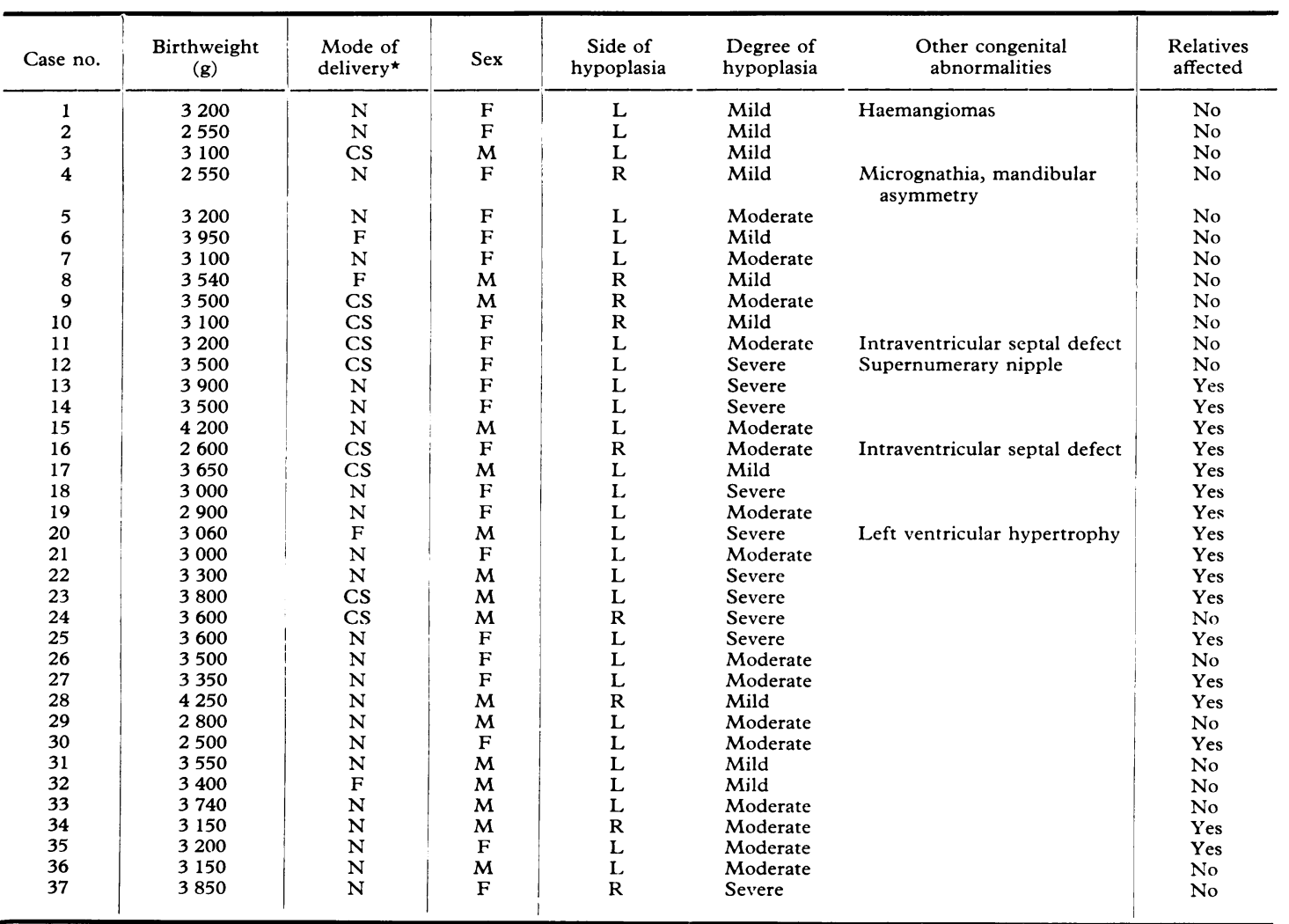

${ }^{\star} N$, normal ; CS, caesarean section; F, forceps. 
hypoplasia of the depressor anguli oris muscle and the Wolff-Parkinson-White syndrome. 17 mothers were primiparous, 10 were parity II, and 10 were multiparous. 24 babies were born spontaneously, high forceps were used in 4 cases, and 9 were delivered by caesarean section. The high frequency of caesarean section is due to the fact that Alexandra Maternity Hospital is a university teaching hospital admitting a high proportion of severe obstetrical cases.

Mean gestational age was 39.8 weeks (range 37-41). Mean birthweight was $3320 \mathrm{~g}$ (range $2500-4250 \mathrm{~g}$ ). 21 babies were female and 16 male. Left-sided asymmetry occurred in 28 newborns and right-sided in 9. Asymmetry, empirically judged, was mild in 11 cases, moderate in 16 , and severe in 10. There was no correlation between severity of the asymmetry and mode of delivery. 3 out of the 37 babies were found to have minor anomalies (micrognathia and mandibular asymmetry Case 4, supernumerary nipples Case 12, and flat haemangiomas Case 1), while 2 babies had intraventricular septal defect (Cases 11 and 16) and in Case 20 there was a ventricular hypertrophy and tachycardia of unknown origin.

Electromyographic studies. In none of the examined cases was spontaneous activity found at rest. In 10 out of the 15 affected and examined newborns there was a paucity of diminution of the motor units of short duration (1-2 msec) and relatively low voltage (usually $100-300 \mu \mathrm{V}$ ) at apparently maximal contraction during crying. In 5 cases no differences were found between the affected and the nonaffected side. There was no correlation between the degree of lower lip asymmetry and the paucity of motor units. In Case 29 when both the triangular and the mentalis (the so-called lower lip depressors) were tested on the affected side, a striking electromyographic difference was found with a normal tracing from the mentalis. In Case 4, however, no differences were found when the mentalis was tested on both the affected and the nonaffected side.

Most of our attempts to measure the latency have been unsuccessful because of the pain evoked by the test and the motion artefacts that follow. In Cases $23,28,29$, and 37 the latency was normal, while in Cases 11 and 19, it was increased on the affected side (9 and $8 \mathrm{msec}$, respectively, against $4.5 \mathrm{msec}$ on the nonaffected side).

Five parents with lower lip asymmetry were tested and in 3 of them (Cases 17, 28, and 30) the electromyogram was normal while in mothers of Cases 19 and 23 there was a slight paucity of motor units on the affected side. No abnormal latencies were found on the 4 examined parents (of Cases 19, 23, 28 , and 30 ) while the mother of Case 17 had slightly increased latencies bilaterally $(5 \cdot 1 \mathrm{msec})$.

In conclusion it can be stated that electrical studies in most cases confirmed the myogenic nature of the syndrome by such findings as paucity of motor units, no fibrillation, no positive sharp waves, no high voltage motor units, and no prolongation of latency. A typical electromyogram of the affected against the nonaffected side (Case 20) is shown in Fig. 1.
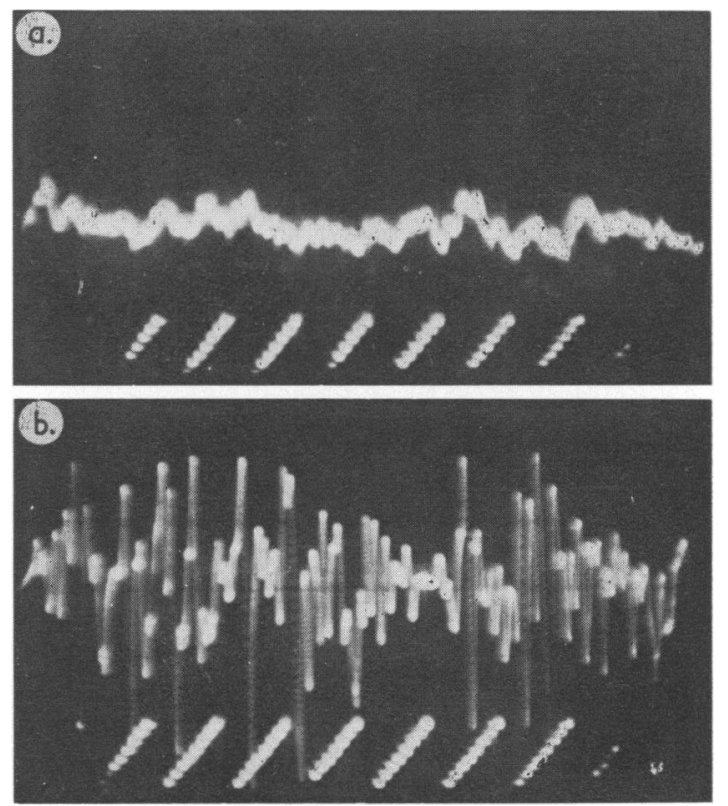

FIG. 1.-Electromyogram of affected (a) against nonaffected side (b) in Case 20.

Family studies. In 17 out of the 37 cases there was a history of a lower lip asymmetry in the babies' first- or second-degree relatives and/or their sibs.

Careful examination of the 37 mothers of the probands showed 11 of these to present lower lip asymmetry. 14 of the fathers were clinically examined and 2 of them were found to be affected. According to information supplied by mothers, another 3 fathers of the probands had a history suggesting congenital hypoplasia of the depressor anguli oris muscle. Thus, among those examined a minimum of 13 out of the 74 parents were affected. Examination of the sibs of the probands was less intensive, but out of 29 brothers and sisters clinically evaluated 9 presented asymmetry of the lower lip. 
Interviews with the mothers of the probands revealed that more than half of the families had one or more similarly affected individuals and in 3 families (Cases 20, 25 and 28) individual cases were diagnosed in consecutive generations (Fig. 2 and 3).

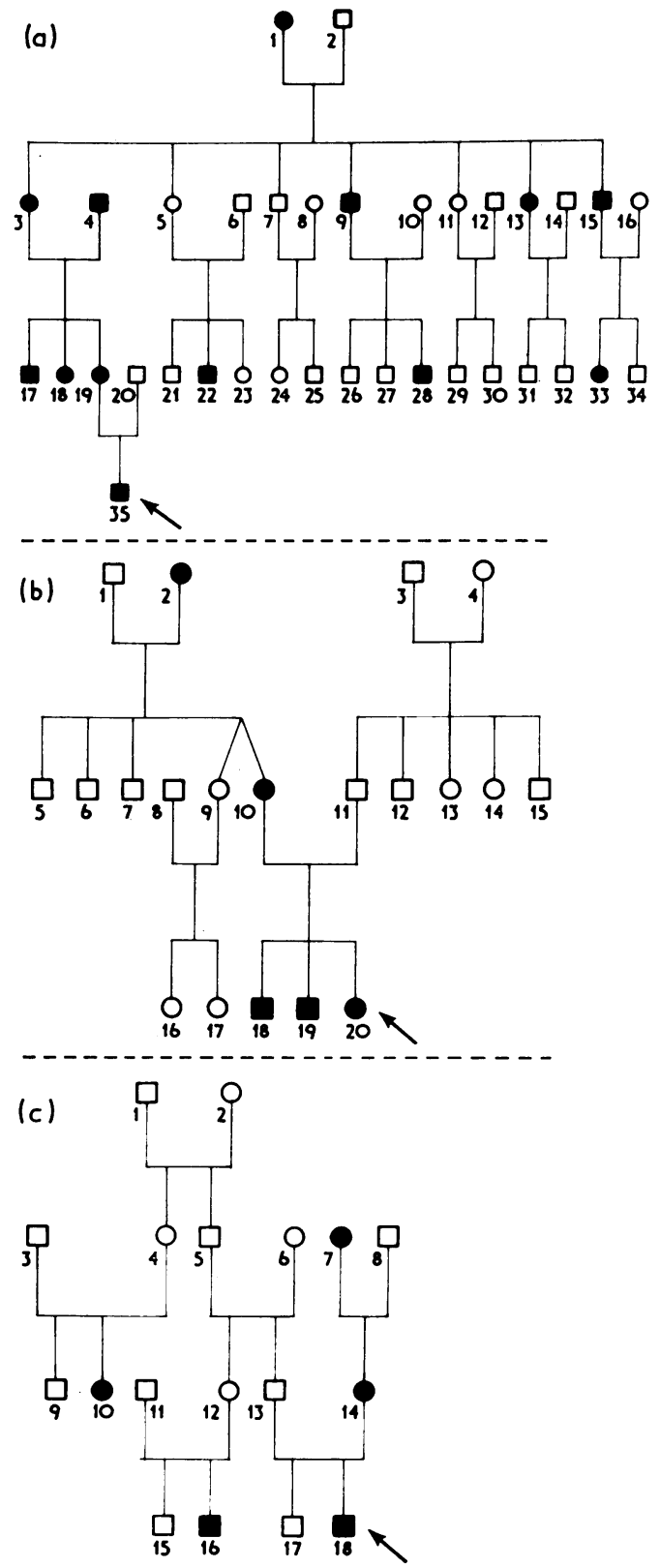

Fig. 2.-Family tree of Case 20 (a), of Case 25 (b), and of Case $28(c)$, indicating affected individuals.
A female twin pair (Fig. 2) who were of similar appearance and who had often been mistaken for one another, and who showed identity with respect to the ABO, MNSs, Rh, Kell, Duffy, and Lewis blood groups were discordant for asymmetry of the lower lip.

No cases of consanguinity were found among the parents of the probands.

\section{Discussion}

Congenital hypoplasia of the depressor anguli oris muscle is not associated with evidence of trauma in the birth process. Perlman and Reisner (1973) reported 41 cases among 6360 newborns, an incidence of $6.5 \%$. Our material, drawn from a prospective survey of consecutive births, gave an incidence of $8 \cdot 2 \%$. Marino (1953) and Nelson and Eng (1972) stated that the anomaly is not rare. Their data, however, do not provide a basis for an estimation of the incidence of this condition. From most of the recently published additional studies no conclusions can be drawn on the frequency of the anomaly as the material used was from general paediatric hospitals and neurological and otolaryngological clinics (Hoefnagel and Penry, 1960; Cayler, 1969; McHugh, Sowden, and Levitt, 1969).

In 3 out of 37 patients facial asymmetry coexisted with other minor anomalies that had no real significance. In 3 instances, however, major congenital defects coexisted with the hypoplasia of the depressor anguli oris muscle. Perlman and Reisner (1973) reported associated congenital anomalies of 2 in 41 cases.

Certainly hypoplasia of the muscle should not be regarded as a sign of comparable value to the finding of a single umbilical artery (Pape and Pickering 1972).

In adults the downward 'droop' of the intact side will most likely be missed unless specifically looked for. In affected relatives the cosmetic defect decreases with age. As Nelson and Eng (1972) stated, it is likely that the asymmetry would be hardly noticeable if the subject avoided broad smiling or grimacing.

The high incidence of affected individuals among the first-degree relatives of the probands suggests that hereditary factors may be involved. The distribution of secondary cases in the families and the fact that two probably monozygous twins show discordance, is strong evidence against any simple monogenic pattern of inheritance and in favour of a more complex aetiology, probably multifactorial. 

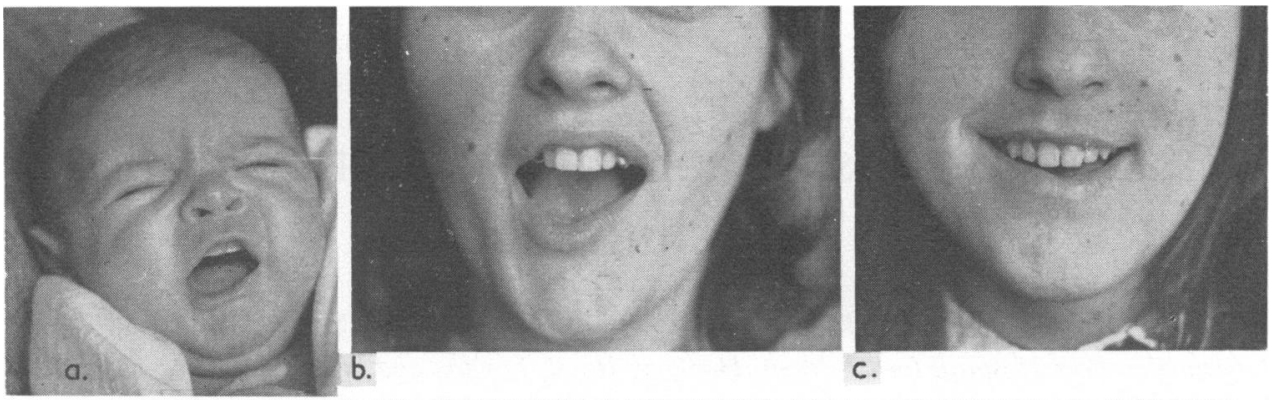

C.
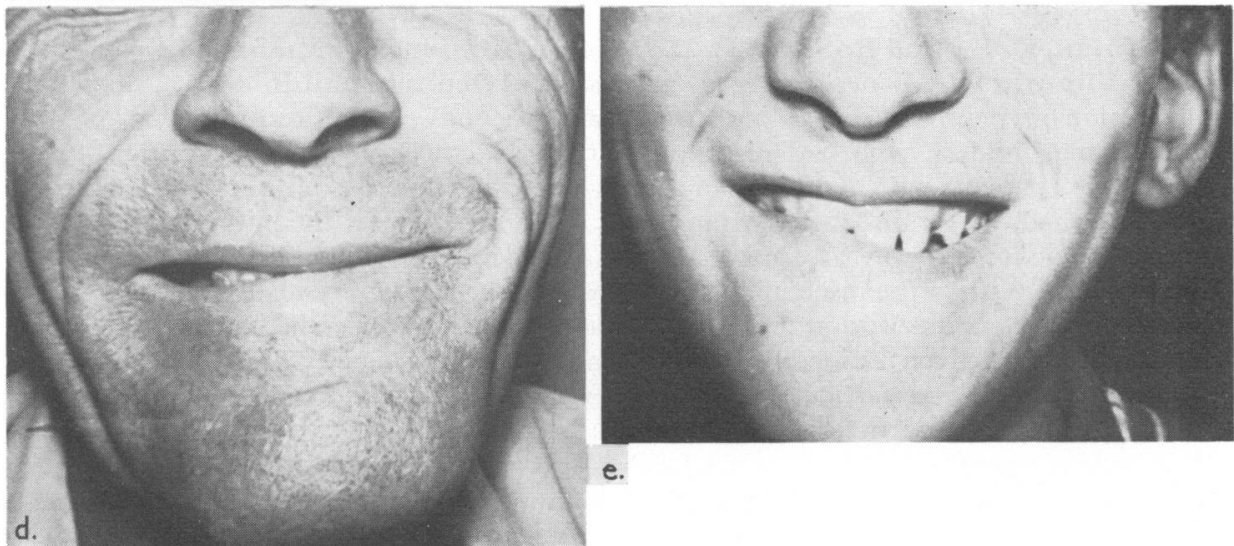

e.

FIG. 3.-Affected individuals from the family of Case 20. (a) Proband, (b) mother, (c) maternal sister, (d) maternal father, and (e) maternal cousin.

The authors are grateful to Professor Mogens Hauge of the Department of Genetics, Odense University, Denmark, and Dr. G. Stamatoyannopoulos, Seattle, Washington, for valuable assistance and critical review of our material.

\section{REFERENCES}

Cayler, G. G. (1969). Cardiofacial syndrome. Archives of Disease in Childhood, 44, 69.

Chantler, C., and McEnery, G. (1971). Cardiofacial syndrome. Proceedings of the Royal Society of Medicine, 64, 20.

Ford, F. (1952). Diseases of the Nervous System in Infancy, Childhood, and Adolescence, 3rd ed. Thomas, Springfield, Illinois.

Hoefnagel, D., and Penry, J. K. (1960). Partial facial paralysis in young children. New England fournal of Medicine, 262, 1126.
McHugh, H. E., Sowden, K. A., and Levitt, M. N. (1969). Facial paralysis and muscle agenesis in the newborn. Archives of Otolaryngology, 89, 131.

Marino, H. (1953). Paralysis of the muscles of the chin: surgical treatment. Surgery, Gynecology, and Obstetrics, 96, 433.

Nelson, K. B., and Eng, G. D. (1972). Congenital hypoplasia of the depressor anguli oris muscle: differentiation from congenital facial palsy. Fournal of Pediatrics, 81, 16.

Pape, K. E., and Pickering, D. (1972). Asymmetric crying facies: an index of other congenital anomalies. Fournal of Pediatrics, 81, 21.

Perlman, M., and Reisner, S. H. (1973). Asymmetric crying facies and congenital anomalies. Archives of Disease in Childhood, 48, 627.

Correspondence to Dr. C. Papadatos, 6 Asklipiou Street, Athens 144, Greece. 